\title{
“Influence” in historical explanation: Mary Morgan's travelling facts and the context of influence
}

\author{
Tiago Mata \\ t.mata@ucl.ac.uk \\ UCL Department of Science and Technology Studies \\ 22 Gordon Square, London, WC1H 0AW \\ +442076791328
}

\begin{abstract}
In my years as a student of Mary Morgan and later as a junior peer, I observed that one concept prompted her to react with caution and skepticism. That common notion was "influence." In this essay I follow her cues to ask what are the legitimate grounds for claims of influence in historical explanation. Morgan's writings have made us aware that the story of social science cannot be captured in simple reckonings of influence, and that long chains of actions are required to seat an idea in the mind, and longer still to set it to paper. My contribution to problematizing influence is to list the pitfalls of its uncritical use but also, once suitably redefined, its potential contribution to analysis. To illustrate my claims I propose a test case, to study the "influence of Mary Morgan."
\end{abstract}

\section{Keywords}

historiography, explanation, communication, social influence, personal influence, sociology of knowledge

\section{Acknowledgments}

I am grateful to the suggestions and criticisms of Mary Morgan and of the participants at the conference "Curiosity, Imagination and surprise" at the University of Utrecht, September 2017. A special debt of thanks is due to the patience and care Marcel Boumans and Hsiang-Ke Chao devoted to that meeting and to this collection. 


\section{"Influence" in historical explanation: Mary Morgan's travelling facts and the context of influence}

\section{Lessons learned}

The reader is cautioned that this essay has a peculiar diction. It was written for a collection celebrating the contributions of Mary S. Morgan and although I strive to maintain a scholarly tone through most of it, I could not hold myself from bookending the essay with confessional anecdotes.

My first confession is a review of what I recall from Mary's supervisions. In my mind I see her sitting to the side of a large office window, ensuring that the brightness from the street would not glare my attention; I see myself slumped in the company of boxes, stacks, and cabinets of print, with photocopies, drafts, issues of journals, and books, old and new. I recall gestures, such as when I was handed a copy of Thomas Gieryn's 1995 handbook chapter on "boundary work," or looking down at one of my essays with heavily annotated margins. By contrast to these vivid impressions, the substantive traces of our meetings faded quickly, a casualty of notes taken on scraps of paper, used and disposed of. More than words of advice and insight burned to memory or copy pasted into my dissertation, I recall taking from those meetings non-discursive markers, what convinced and didn't convince Mary, what she thought promising and what she treated as trivial. These were the signposts of my graduate education.

One signpost was Mary's disapproval of the concept of "influence." "Frank Knight influenced Milton Friedman" were my words on a short essay for her graduate seminar, a suitably plausible, sophomoric and unsubstantiated claim. What surprised me in her reaction was that it was the form, not the substance of the claim, that drew her skepticism. It intrigued me and stuck with me. As an undergraduate student in economics I was taught the history of the discipline as a scheme of schools and authors whose ties were made of a thing called "influence." The history of economics without "influence," I thought then, was a disjointed collection of lives and writings. Rejection of the term became for me an encouragement to look for replacement narrative threads. After graduating from being her student, I overheard Mary speak against the notion of 
"influence" numerous times. Now, I, the mature scholar, greeted these with a complicit smile.

This occasion grants me the opportunity, for the first time, to earn this complicity. Although I felt I was in on a special insight, I have never spelled out what this might be. The purpose of this essay is therefore to make the case against the abuse of "influence" in the history of social science. Firstly, I argue that in its most common definition the term freights a conception of ideas acting at a distance implying that individuals capitulate to the power of ideas. By deploying this notion, scholars foreclose the study of communication. To bring these difficulties into sharp relief, I contrast the casual influence account with Mary Morgan's “travelling facts” approach. Secondly, I want to partially redeem influence, and look to some classic writings in social psychology to make a positive case for its use. I contend that "influence" can be redefined into multiple working concepts that aid our understanding of interpersonal relations. In sum, I reject "influence" as a pseudo causal account of ideas at a distance, and adopt influence(s) as a term of description of social interaction. Finally, to illustrate the parsed meanings and uses of "influence" I look to Mary Morgan's scholarship as a tentative test case.

\section{The case against influence, getting closer to practice}

Influence is a term in common scholarship use. A query of the term in two of the most comprehensive academic databases - Jstor and Web of Science - reveals that its use count has increased ten fold in the past 50 years. ${ }^{1}$ Figure 1 shows an even starker increase in use obtained by querying Google Scholar. The pattern of growth is confounded by the total increase in academic literature. Estimates of the volume of academic print vary, Larsen and Ins (2010, following the seminal work in Price 1963) record a doubling every 17 years, Bornmann and Mutz (2015) have estimated a faster pace, a doubling every 9 years. While the study of the stages and pathways of the term's acceptance into academic lexicon is a fascinating subject, it is beyond the scope of this

\footnotetext{
${ }^{1}$ Both Jstor and Web of Science offer partial vantage points into academic print. Jstor hosts back issues of more than 2,400 scholarly journals across 60 disciplines, with a primary focus on the humanities and social sciences biased to the most prestigious and older titles. For recent years its coverage is not uniform as it is limited by separate agreements with publishers. Web of Science claims over 20,000 journals in its collection with records going back to 1900 . It is specialized in the natural sciences, including an increasingly large number of social science titles but virtually no humanities journals.
} 
essay. For my semantic interests, it suffices to note that the term is in wide use across history and the social sciences, indeed across all of scholarship.

\section{FIGURE 1 HERE}

The term is not only frequent but also eminent. For sixty years "influence" has emblazoned the cover of one of history of science's most prestigious journal, Isis. In 1953 George Sarton stepped down from the editorship of the journal he had founded for the study of the "History of Science and Civilization," and Isis updated its motto to "International Review devoted to the History of Science and its Cultural Influences." Isis's summer supplement is similarly titled as the "Current Bibliography of the History of Science and Its Cultural Influences." No journal in the history of economics declares "influence" as its subject, but the term is in wide use. In the last 20 years it appeared over 83 times in abstracts at History of Political Economy, 52 times in the Journal of the History of Economic Thought and 39 times at the European Journal of the History of Economic Thought. Isis's subtitle refers to science's grip on culture but in the history of economics the common use is for influence to describe a relationship between works or authors. One finds it in titles such as "Thomas Hobbes's Influence on David Hume: The Emergence of a Public Choice Tradition" (Moss 1991); "Aspects of the Influence of Francis Hutcheson on Adam Smith" (Pesciarelli 1999); "On Ricardo's Method: The Unitarian Influence Examined" (Depoortere 2002). ${ }^{2}$

In the historiography of economics the term's meaning is congruent with the vernacular. The Latin etymology of "influence" connotes an inflow. The term was used to denote the astrological belief that the motions of stellar bodies determine the fate of men (of a tamer quality than the phrase "under the influence" that requires a stronger spirit than cosmic ether). The Oxford English Dictionary records that at around the same time that the causal power of constellations and planets was being noted, influence began also to

\footnotetext{
2 Depoortere (2002) is a critique of Cresmachi and Dascal (1996)'s claim of an influence by Thomas Belsham and Joseph Priestley on Ricardo's methodology. Depoortere argues that Ricardo was too much of a religious skeptic to warrant this flow of influence, and that his methodology is incompatible with the two men's take on Newtonianism.
} 
describe the power of men over other men. Like the spirit of the time, zeitgeist, influence calls upon an imagery of invisible flow that defying insulation and isolation crosses time and space. In intellectual history, ideas grip ideas in orbit with a mysterious force, like gravity, without explicit mechanism.

Philosophers have considered influence in accounts of causation, often casting it to ancillary roles. While "explanation" and "causation" get (multiple) entries in encyclopeadias of philosophy and the humanities, influence gets mentions within those entries and has not originated a substantial body of critical literature of its own (e.g. Woodward 2017). One early formulation is found in Thomas Aquinas who understood the work of art as made by proximate causes, e.g. the artist that makes the work, but also remote causes such as the work's intended use, or its constituent materials. In history of art, reworkings of this proposal of "influence as remote cause" in a causal complex remain viable albeit not popular (Ambrose 2012, see also and more critically Kramer 2011). Two decades ago the term was revived in David Lewis' much debated counterfactual account of causation. To address the objection of preemption, Lewis (2000) replaced his definition of cause as counterfactual dependence (had C not occurred, E would not have occurred) by a relation of influence ( $C$ causes $E$ iff small changes in $\mathrm{C}$ cause large changes in $\mathrm{E}, \mathrm{C}$ and $\mathrm{E}$ being start and endpoints of a causal chain). In that debate influence is an abridgement to the idea of a intricate causal chain.

My dissatisfaction with influence lies at the heart of what as made it so deployable in history and in the accounts of causation, the possibility of action at a distance. ${ }^{3}$ I worry about what gets lost and unexamined. Consider Moss's "Thomas Hobbes's Influence on David Hume: The Emergence of a Public Choice Tradition." Moss chooses the noun, not the verb. He is interested in the similarities in the social theory of Hobbes' Elements of Law and Leviathan and Hume's Treatise of Human Nature. He is uninterested in the mechanism that bridges authors and times, Hobbes passed in 1679, Hume was born in 1711, they "met" only through print. The worry that Hume's debt to Hobbes was never acknowledged is deflected with the suggestion that it was impolitic to celebrate Hobbes

\footnotetext{
3 My objections are similar to those critiquing Lewis's "causation as influence," see in particular Schaffer (2001) and Bigaj (2012) who call for effluence, for a physical connection holding the causal chain together.
} 
and/or that the message might have been carried through reading Bernard Mandeville. ${ }^{4}$ For Moss, as for many historians of social science, it is a trivial affair that ideas move in time with irresistible force, and therefore he misses out on all the action. He contrasts starting and end-points of a journey but never ask about the journey itself.

I have elsewhere argued that we must ask how books are made, circulated, and read (Mata, forthcoming) and that the journey of social theories might be problematized as acts of communication. In this essay I want to take a different approach to this problem, and highlight how Mary Morgan offers us a fuller and more robust account. Asking "how theories change" Morgan trained our attention to the practices of social scientists. Her distinguished scholarship on modeling highlights the craft and the tinkering of research (e.g. Morgan 2012). She gets as close as any historian can get to the labors of making toy economies. But Morgan's most penetrating contribution to the puzzles of knowledge transfer came with the Leverhulme Trust project on "How Well Do Facts Travel?" (see Howlett and Morgan 2011).

The principal subjects in that major study were facts, "shared pieces of knowledge that hold the qualities of being autonomous, short, specific and reliable." (Morgan 2011, 8) Facts by this definition are thing-like. ${ }^{5}$ The project described perilous journeys where facts "may not travel entirely intact without some kind of wearing down, rounding off or enriching and sharpening" (ibid., 17,18). Facts in transit suffer injuries and enhancements or the sheering of "wooly details." The metaphors are mixed and uncommital. Facts are matter that wears, wooly creatures and later human characters, when they reveal themselves to be stubborn, chameleons, brokers, mediators, and "well-travelled" if they "have acquired and lived a life of their own" (ibid., 25). Morgan's proposal is that we accompany facts to appreciate the multitude of actors that they encounter and that contribute to their mobility and fecundity. If the imagery of

\footnotetext{
${ }^{4}$ In his defense, Moss calls on the work of Paul Russell whose writings on Hume's Treatise are extensive and deservedly admirable. However, Russell's (1985) specific argument that behind Hume's organization of the Treatise lies Hobbes' plan for Elements of Law seems to me somewhat strained. The superficial similarities between the tables of contents of both books are evident but also generic. Russell's assertion relies on difficult to reconcile claims: that Hobbes was well known and toxically controversial, and that in such a context it was safe for Hume to use the structure of Elements of Law without anyone noticing the debt. Friends or foes of Hume never made that connection.

${ }^{5}$ Facts as things contrast with Mary Poovey's (1998) history of the fact as a genre.
} 
"influence" takes us to astrology and heavenly bodies acting at a distance, for the "travelling facts" account the imagery is gardening. When wisely handled facts bear fruit. The subtitle of the essay collection that concluded the Leverhulme project calls these studies in knowledge "dissemination."

In the "travelling facts" account, integrity outstrips influence as the crucial concept. Facts must be well identified, so that we can distinguish between them and recognize them in their travels. A fact is a kernel of knowledge that is labeled and packaged, with companions that preserve its integrity. In table 1 I set side by side the distinguishing features of the "casual influence" and "travelling facts" accounts. The influence account has a restrained ontology. It is populated by ideas, concepts mainly, and by scholars who think them. By contrast the travelling facts account is agnostic about what exists in the world, and grants agency to the material culture of science, to institutions, as well as to individuals. The most striking differences appear when we consider how these accounts explain historical change. Influence operates on the resemblance of ideas, and has little to say about the mechanism that leads to their adoption, although one might also find appeals to systematicity (of some kind) as if ideas inevitably develop towards coherence. The "travelling facts" account imposes the prior identification of facts and that they travel with integrity before it looks for an association, and it has a simple explanation for successful time travel. A fact disseminates if it suits the practices and purposes of its new location and if it bears fruit.

Table 1 goes here

To write the history of economics as emanation of ideas, as influence, is often times an invitation to grand narratives of ideas that insinuate themselves onto the minds of eminent men. As John Maynard Keynes cryptically formulated in 1936, from their graves economists enslave practical men in authority. The alternative to this necromancy is to study economics as inseparable from the activities of scholars who assemble (and disassemble), tinker, carry, usher (art-e)facts. By shining a light on travel 
and craft, Morgan has laid out a history of social science that is empirically rich and unelitist.

What has been called "influence" is at best an annotation of a pattern the analyst observed in the historical record, a likeness that because is removed in time, place and personnel cannot be told in a simple causal tale. Charitably these similarities signal a puzzle for closer study. "Influence" offers no explanation and no road map of how to proceed in solving the puzzle. By contrast, the framework of "travelling facts" can guide a study of how knowledge moves in time and space and it has the additional advantage of facing head on the paradox that knowledge is not only portable but also mutable when in transit. 6

I write about "influence" because of Mary, who sparked my curiosity about this problem. While writing this piece I discovered that Mary's attention to this matter began with M. Norton Wise's dissatisfaction over one of the most influential texts of 1970s history of science. In a magisterial study of 1971, Paul Forman argued that Weimar physics "capitulated" to an acausal account of the natural world because of the cultural dislocations of the period. The spirit of the Weimar Republic influenced a major reorientation of the physics discipline. Besides disagreements about evidential claims, e.g. the alleged "suddenness" of the change, or the description of "monolithic vitalism," Wise was troubled that Forman's thesis dehumanized actors. Individuals do not usually endure the inscription of culture upon their lives and work without resistance and angst. In Wise $(2011,427)$ 's words “that we choose our influences, or at least that they depend on our susceptibilities." Wise's counter proposal is to honor the subjectivity of historical actors like we do our own, conceiving them as thoughtful participants in culture and polity. ${ }^{7}$

\footnotetext{
${ }^{6}$ Bruno Latour has famously argued that science commands the world through the circulation of "immutable mobiles." Latour's argument is less compelling when looking at social science, where mutability can be an asset for social and cultural mobility.

7 The reader might note here a mind-bending irony. The reader is faced by a piece protesting that "influence" is an acausal account of intellectual change, because it brackets out of analysis communication and lacks determinate mechanisms. At the background of this critique is Wise's plea to abandon causal stories such as Forman's analysis of how Weimar culture influenced the adoption of acausal physics. While Norton Wise objects to influence because it is causal, I object to it because it is not causal enough.
} 
In sum, "influence" fails the historical enterprise by dressing up as explanation, all the while it is foreclosing understanding of how knowledge and culture are made and renewed. Wise's worries about the suppression of subjectivity seem to me a corollary to my indictment of unexamined action at a distance. A claim of influence trivializes individuals' struggle with the callings of the past and the urgencies of the present. To confirm how rich this vein is, one need only look to Harold Bloom's 1973 The Anxiety of Influence. Bloom analyses the poetic enterprise as beset by the shadow of the canon, each poet struggling to position herself against that past, striving for release and originality. The casual use of influence in historical explanation hinders our understanding of communication, fact and subject.

\section{The case for influence, examining interpersonal relationships}

I have so far discussed influence as meaning a bond between two distant actors or texts. There are other definitions, where influence has no distance to traverse and comes to life when individuals interact. In this alternative frame, influence is one among many features of interpersonal relations. In this section, I read some classics of social psychology to distinguish influence that is personal from influence that is social, and to argue why both deserve greater consideration in historical discourse.

The twentieth century's most popular treatise on interpersonal influence is a self-help book. Written by the Machiavelli in the age of Reader's Digest, Dale Carnegie's How to Win Friends and Influence People (1936) was a publishing sensation, updated, revised, in and out of copyright numerous times, and translated to countless languages. It treats its readers to sets of maxims they can recite on the way to an office meeting or to a dinner date. Carnegie advises that to "Win People to Your Way of Thinking" requires following 12 rules (listed in table 2). Carnegie's advice bundles politeness ("show respect," "see things from the other's person's point of view") with emotional manipulation ("let the other person feel that the idea is his or hers"). The book mentors persuasion in one-toone situations and its (not so) secret weapon is to appeal to your interlocutor's self-love. Carnegie follows his own advice by promising his readers that the final outcome of his program is that they will be liked. Reading How to Win Friends and Influence People we encounter influence that is not accidental and far-reaching rather is the designed effect of a staged and up-close performance. 
Table 2 here

As it is customary of the genre, How to Win Friends oversold how a few precepts could win arguments and affections. For Carnegie, neither the arguments nor the character of individuals involved were as significant as the mastery of the conversation. Around the same time he was codifying a universal art of influence, social scientists were adopting personal influence as a research subject. They turned to it in the unlikely setting of the study of mass communication, and focused on what Carnegie had elided - who and what is communicated and under what social conditions.

In the mid-1930s, as Franklyn Delano Roosevelt broadcast from his fireside, and more worryingly, fascists across Europe used radio to regiment a mass public, the question arose of how effective was mass communication? The Bureau of Applied Social Research at Columbia University led by the Viennese émigré Paul Lazarsfeld took up this problem and upon it built itself institutionally and reputationally. Lazarsfeld's studies and akin "voting studies" deflated claims about the powers of mass propaganda. They championed a model of "two-step flow of information" where "opinion leaders" were required intermediaries for the efficacy of communication. I see a parallel between my efforts to bring influence down from the heavens and into the realm of social relations and early media sociologists replacing a belief in the overpowering force of broadcast media by a more layered, empirically sound conception of communication.

One of the Bureau's landmark studies, with echoes of the Lynds' Middletown, focused on a seemingly insulated Midwest community of 60,000 people, the town of Decatur, Illinois. The methodology of the Decatur study, conceived by Lazarsfeld and implemented by C. Wright Mills together with a vast team of women researchers remains a blueprint for the study "personal influence." In the course of several months 800 women were repeatedly interviewed about their views on marketing (e.g. coffee brands), fashion (e.g. whether to wear a hat), public affairs (e.g. voting), and movies. The consumer and civic choices were not of primary interest rather they were preliminaries 
to identify "opinion leaders" who "casually exercised, sometimes unwitting and unbeknown" influence (Katz and Lazarsfeld 1955, 138). Through the interviews researchers evaluated "the impact of personal contacts as compared with the impact of mass media." (ibid., 166) They found that subjects had high exposure to conversations about consumer goods and movies and that these were consequential for their choices. By contrast, although highly exposed to newspaper reviews and movie advertising these had negligible impact on what the women of Decatur watched. Only radio seemed to have the potential for low exposure with high impact and only in the domain of consumer marketing. The final component of the study was to identify "influentials" (1549 were named and 634 interviewed) and classified by lifecycle (age, family status), social and economic status, and gregariousness. The study could then evaluate, for instance, how youth contributed to becoming influential on fashion attitudes.

Through the airwaves or cheap print the media is an instance of action at a distance. Lazarsfeld's claim was that media messages would grip individuals only if relayed by friends, family and acquaintances that deliberately took it upon themselves to sway opinion (as Carnegie coached in his book) or, more commonly, did so without intelligent design. ${ }^{8}$ I propose that the Decatur study and its definition of "personal influence" are a serviceable analogue to address some unanswered questions in the history and sociology of science.

High on the agenda of Lazarsfeld and associates was assessing the efficacy of mass communication, plotting exposure against impact. Contemporary scholars, and those that administer them, are fond of "impact," which they measure in the currency of citations. Citations can be weighted by year (e.g. i-index) or indexed with consideration of research volume (e.g. h-index). One can draw citation networks and describe their demographics. However, we scantly understand how scholars encounter and digest

\footnotetext{
8 The Bureau's findings at first appeased anxieties that control of the media, by political or commercial interests, posed a threat to democracy and personal autonomy. Within a few years the results were being read differently. Todd Gitlin (1978) asked is the media so powerless when it claims still over $50 \%$ of observed attitudinal changes? Can individuals really be leaders of opinion if they are relaying media/marketing messages? Finally, are media effects and personal effects of the same kind? The latter can be measured by changes to attitudes, but Gitlin argued that what makes media powerful is its framing of issues, of questions asked and of concepts carried.
} 
information and choose to cite. A correlational study of citations cannot answer such questions, only an interview (or observational) study of scholars can discriminate and evaluate the sources of scholarly communication and gauge the extent of exposure against their efficacy.

The analogue for Decatur, an "average" community standing in for the United States of America, in a study of scholarly communication would be an University sampling its many faculties, departments, and research staff of various levels of seniority. The interview protocol might enquire about citations practices together with questions about research and teaching activities over a period of months. Then a further set of interviews would probe whether actions arose after a conference discussion, a conversation with a lab or departmental colleague, an online search, listening to a public lecture, or encountering a new issue of a journal. Only a few of these would be, genuinely, "personal influence," i.e. personal contact trumping other sources of information and persuasion.

By setting "personal influence" alongside other forms of scholarly communication, academic periodicals, online social media, seminars, we begin to map the channels of scholarship. It is a safe prediction that, like in the Decatur study, formal communication would be humbled by evidence of its limited powers. While the "travelling facts" account unveils journeys, this type of study would sketch the topography upon which travel is happening - telling us what types of content are readily accessible and which require aid to overcome disbelief or doubt. Like the Decatur study we could ask what are the classes of personal influence, does seniority and authority correlate with leadership in scholarly opinion, what about gender and role within the University administration?

The Decatur study suggests how one can conceive influence away from causal stories as a behavior and as a capacity of certain classes of individuals. Reimagining the Decatur study as a study of State University of Nowhere Special is an exciting prospect. I am aware that an interview study of this scope would be onerous and difficult to fund, fraught with problems of generalisability and of access to informants but it would examine how formal and informal communication interact in a depth and detail that 
citation analyses cannot rival. The empiricist outlook of my imagined study agrees with the "travelling facts" account although it seats the researcher as overseeing the social system of a University rather than following a fact as it meanders through science and society. Both conceptions take social processes and dispositions as pre-determined, in one the fact is led along by the practices of social scientists, in the other information is weighed by the salience and authority of various kinds of informants. But this approach need not exclude subjectivity. "Personal influence" can be a resource in identity politics, as we choose who influences us or set out to try and influence others, in both senses a way to participate in making culture.

As reading Dale Carnegie reminds us, not all interpersonal interactions resolve into equitable and rewarding experiences and social psychologists agree. Some of the seminal works revealing how interpersonal contact constrains action include the experiments of Solomon Asch $(1955 ; 1956)$ in which subjects gave flawed testimony to conform with the group. Even more shocking was Stanley Milgram's experiment (1963) where most experimental subjects were presumably willing to electrocute someone to death on the command of a lab instructor, no persuasion required, merely the semblance of authority and persistence. Spectacularly, in Philip Zimbardo's Stanford Prison experiment no direction was necessary for subjects to adopt their assigned roles of prison guard and prisoner and exhibit behaviors of emotional and physical abuse (Haney et al. 1973). These classic studies are explicitly concerned with conformity not influence. The situations contained limited verbal interaction and no persuasion, and our attention is directed to those that complied, not to those that dissented. I refer to these well-known studies to stress experimentally what we know experientially, that autonomy is not always honored in social intercourse. To unpack collective acquiescence in the history of social science I propose that we develop a concept of "social influence."

To explain what I mean by "social influence" I call upon another classic text of social psychology that, unusually, eschewed experiment for participant observation. Unlike the Decatur study this team of researchers did not announce itself to its subjects, and in what was permissible practice in the 1950s, infiltrated their subject group, a religious cult. The cult formed around a Mrs. Marian Keech (not her real name) whom through 
automatic writing had revealed a series of millennial prophecies. Mrs. Keech claimed the messages were broadcast to her by superior beings from a planet called "Clarion." The aliens had visited Earth in flying saucers and with their superior technology discovered fault lines in the planet's crust which on midnight December $21^{\text {st }} 1954$, would create a flood spreading from the Great Lakes to form an inland sea stretching from the Arctic Circle to the Gulf of Mexico, and ultimately submerging all of the Americas. The believers would be rescued from the flood by the aliens, whom they called the Guardians.

Researchers at the University of Minnesota took notice of the cult by reading about it in a mocking newspaper report and set out to observe how the group experienced the trauma of a failed prophecy, "dissonant with continuing to believe both the prediction and the remainder of the ideology of which the prediction was the central item." (Festinger, Riecken, and Schachter, 1956, 27) In the resulting book Leon Festinger and colleagues describe the members' substantial investment on Mrs. Keech's prophecy. Many left their jobs and sold property, and more mundanely, on the fated night they shed all metallic implements from their bodies, in anticipation of being lifted to safety in flying saucers. It became a seminal contribution to the study of "cognitive dissonance" (Festinger 1962). ${ }^{9}$ To the question of how do collectives handle the trauma of disconfirmed belief, Festinger answered that once secretive groups turned to overt and energetic proselytizing. The logic of this response was that "if more and more people can be persuaded that the system of belief is correct, then clearly it must, after all, be correct." (Festinger, Riecken, and Schachter, 1956, p. 28)

One can parse influence of various kinds in the Clarion story. The aliens inducing Mrs. Keech to automatically write "lessons" for the group are an instance of cosmic, at a distance, influence. Personal influence is also evident, for instance in Edna Post's domestic choices that correlate with Mrs. Keech's and Dr. Armstrong's interventions, the cult leaders. But we also encounter influence in a novel sense. When the group's central ideology is under threat, a cult member's conviction is repaired by the reassuring observation of the cult's grip on others, by the permanence of old members

9 To read an evaluation of forty years of cognitive dissonance research and theorizing see Dein (2001). 
and by the making of new recruits - even if these were undercover ethnographers from the University of Minnesota. Influence in this third sense is a manifest quality of the group, hence the label of "social."

What I take from the Clarion study is an example of how we might study the expression and (re)direction of collective belief and belonging. The absence of a guiding prophecy did not terminate the cult. Initially collective purpose was invested on preparing for the alien rapture, but after the failed prophecy the group aims its sights towards publicity and proselytizing. The new direction did not result from the sum of distinct acts of personal influence between leaders and followers, it emerged in an unintended and genuinely collective way. The analytical attraction of the notion of "social influence" is thus to set aside questions about who is responsible for the change (I blame the aliens) to examine what goals, practices and values mobilize group cohesion.

The falsification of belief and the resistance to change beliefs have been a longstanding concern of the history and philosophy of science. Social science offers us numerous instances of prophecies and predictions that require regular reediting and maintenance -in macroeconomics for instance, Philips curve and lagged quantity theory of money, to name only a couple. Thomas Kuhn (and Imre Lakatos) explained resistance to "anomalies" by reference to institutional or metaphysical structures of scientific enquiry - schools, paradigms or hard cores of beliefs, scientific communities sheltered some of their processes and meanings from review. Kuhn was reluctant to invite sociological or psychological accounts of science, and it was for others to make that leap, for instance Edwin Boring (1964) and in a major review essay Michael J. Maloney (1979). These were roads not taken. In the years that followed interest in psychological explanations was overtaken by methodologies that balance non-human actors against humans and their motives in the making of science. My invitation is to look away form the tally of beliefs held and lost, and write a history of discarded ideas that, inspired by the Clarion study, look at how groups mobilize once beliefs come under threat.

My review of some mid-twentieth century social psychology classics illustrates how we might redeem influence not as one, but as multiple analytical categories that unpack 
interpersonal relations. ${ }^{10}$ Other definitions and research agendas are possible, I outlined only two which I labeled "personal influence" and "social influence" and summarize in table 3. The "personal influence" agenda asks us to compare the channels of scholarly communication and to assess how personal contact enables and obstructs formal communication. Inspired by the Decatur study, I envisioned a protocol of structured interviews followed by qualitative panel data analysis. By contrast, the "social influence" agenda sheds light on the fabric of social cohesion and the strains of challenged belief. The methodology is necessarily ethnographic, whether covert, overt, or archival, the crucial observations are obtained by peering into the fabric of interactions of a collective and inquiring about what animates it.

Table 3 here

When I made my case against "influence" I argued that historians were drawn to the concept because it seemed to promise a casual causal story that collapses time and space. With that criticism as background, this section exemplified how we might begin to claim "influence" as a concept of closeness that unpacks interpersonal relations. My strategy was to turn to the history of social psychology to elicit new meanings for the concept of "influence" discussing how they might open up to empirical analyses of the worlds of social science. I have kept Mary Morgan's “travelling facts" account away from view because I consider it removed from the puzzles I pose in my case for influence. But next I return to Morgan's work with a different purpose, using it to illustrate the research approaches that I have anchored to different meanings of "influence."

\section{A case study: the influence of Mary Morgan}

Under the casual and cosmic definition of influence, it is premature to evaluate the influence of Mary Morgan. We must wait 50 or even 100 years before an historian is able to reveal to her readers that underlying some noteworthy work in philosophy,

\footnotetext{
10 I have implicitly argued that the late 40 s and 50 s was a period of attention to the psychological underpinning of conformity and authority and that as a result "influence" was being problematized and enriched with meanings and perspectives. One hypothesis, for another essay, is whether this attention contributed to a surge in the use of the term.
} 
history or sociology of economics is the imprint of Morgan's scholarly outlook and oeuvre. This is the type of influence claim I have derided, one that is in the eye of the beholder, that races past explanation and plays to the surprise of distance.

In place of action at a distance I suggested that we get closer to actors and study interpersonal relations. My first proposal was around "personal influence" as the term was elaborated in early sociology of communication. The main preoccupation of that literature was with impact. Under the standard measures, Morgan's scholarship is having a remarkable impact (see table 4). Her 1999 book with Margaret Morrison Models as Mediators has over 1000 citations, and her single authored History of Econometric Ideas is close behind. The recent book The world in the model is quickly accumulating citations although not as quickly as her hit in management studies a 2010 article entitled "Business models as models." Contrast her scores with those of scholars of her generation, field of expertise and comparable markers of esteem and the eminence of her work is apparent. Unnamed professor of economics at Eastern American University gets half of the citations (most cited work at 531 cites), professor of economics at British University gets one quarter of the scores (most cited work with 273 cites), and the same for professor of philosophy at North American University (most cited work with 248 cites). After numerous queries of the grandees of the history of economics, I found only one professor at mid-western University with scores superior to Morgan's, if one were to exclude his two top titles their citation counts would be matched.

Table 4 here

I have called for comprehensive studies of scholarly communication where exposure and effectiveness of various sources of information are evaluated. In my discussion of the Decatur study I suggested that direct and personal contact shapes attitudinal change, for instance scholars choices of whom to cite. If I persuade a colleague to reference Morgan's entry to volume 7 of the Cambridge History of Science, then it is I who has 
influenced but it is Morgan that gets the citation. ${ }^{11}$ In my alternative frame of reference, Mary Morgan's influence is not measured by how many times she is cited by rather by whether and to what extent she impacts on the citation choices of her peers.

Personal contact in scholarship is an important, and unexamined, dimension of scholarly communication and its traces are difficult to discern from scanning bibliographies. The measure of Morgan's "personal influence" is taken by the advice she has given others of what to read and how to frame a research problem. That influence is expressed in the work of her graduate students, her colleagues, and those she encounters in workshops and conferences. There is nothing remarkable about being an academic and having students, colleagues and attending workshops and conferences and although we all do it, not all of us hold the attention of our peers. A proxy of this "personal influence" are the times Morgan earns mentions in acknowledgments of papers, book and dissertations. To add a personal testimony, I have never met Thomas Gieryn but cite his work manically, a work I discovered at Mary's suggestion, read with her and then benefitted from her continued prodding, asking me to be explicit about my uses of "boundary work" and encouraging me to draw maps. I don't know if Gieryn approves of my cultural cartographies of economics, but I know how Mary feels about them.

Even without a careful survey of the LSE and other London Universities, it should be uncontroversial that Morgan is an "influential" within the communities she inhabits. I am less certain on how to describe the character of that influence - is it expressed in the adoption of certain historiographical approaches or is it a more determinate impact promoting a set of works to her colleagues and students? More interestingly, what are the grounds for Morgan's capacity to influence? Is it her seniority in the field, the particular intellectual niche she occupies as one of the first historians of econometrics

\footnotetext{
11 I wish not to be misunderstood as deflating Mary's achievement, revealed by these citation scores. Only a small proportion of those who cite her will have met her and encountered her work that way. Having known Mary for over a decade and a half, she has never found an occasion to promote her work with me, and I have never seen her do this with others. Therefore the bulk of the attention and regard her work receives is earned by scholars reading her work and recommending it. My purpose in this section however is not to celebrate her deserved acclaim, but to use her work and career as illustration for my earlier claims about influence and interpersonal relations in academia.
} 
and modeling in economics, is it her position of institutional esteem as Professor at the London School of economics, leading member of the History of Economics Society, or as Fellow of the British Academy? That question calls us to interrogate those she influences. What kind of authority impresses them, and what kind of aid they seek when they approach her?

Without extensive data collection my evaluation of Morgan's "personal influence" is indeterminate but I hope it conveys to the reader the value of thinking about how information flows in academia, and in particular in the history of economics community. Formal scholarly media in the history of economics has expanded greatly in the past 30 years. The journal History of Political Economy is still regarded as the most distinguished but lost its position of dominance. With a dozen journal titles and a few books series competing for attention, there is plenty of new scholarship to keep up with, and to it one must add work in neighboring fields of history and philosophy. There are no formal resources to audit emerging topics and approaches, therefore signaling is sought in the judgment of colleagues. Someone like Mary Morgan, who commands packed seminar rooms at learned society conferences and whose conversation is courted in the breaks.

It is less straightforward to illustrate through the work of Mary Morgan the study of "social influence" but difficulties are revealing. I have proposed "social influence" as a useful concept to inquire on the communal life of scholarship. While I had no survey data to rely upon for my discussion of "personal influence," for the study of "social influence" I am ideally placed. Having spent years of my career in Mary's company, I have been an unwitting participant observer. Review of my mnemonic data indicates that unlike Marian (Keech), Mary (Morgan) commands no cult following. Historians usually work alone, against that convention Morgan has co-authored many works, participated in research initiatives and led a few, such as the "travelling facts" project mentioned earlier. She has organized conferences and edited collections (holding the record of most special volumes of History of Political Economy) that relied upon relationships of collaboration, investment and shared belief. And yet, despite her unusual collectivism there is no community with Morgan at its core. 
There are plenty of scholarly cults in the history and philosophy of science and even a few in the history of economics community, so this absence is not a feature of the field. I believe that this absence speaks to Morgan's resistance to the lure of collective purpose and shared belief which I associated with "social influence." Mary rarely places herself at the center, almost never asking the first question, never directive, she carefully listens, supports the ideas of others on their terms - however doomed their enterprise might be - and she surprises and disrupts, pressing you to pay attention to your argument and evidence. Mary prods and challenges. She provides the cataclysm but she is also at hand to provide relief. Mary has studiously avoided the situation of "social influence" developing a body of work that although referenced and admired by many has no hint of prophecy or manifesto to it. Her elegantly crafted, thoroughly researched scholarship makes its way in the world without courting allies and haranguing antagonists.

Contemporary sociology knowledge is fond of the maxim that scientific achievement is a result of a reconstitution of the social, through boundaries drawn, and identities remade. Mary's success cannot be explained this way. Perhaps appropriately, the best account to measure Mary's success is an account that she herself articulated, "travelling facts." She has been able to craft kernels of knowledge about the practice of social science that are robust for travel and fruitful in manipulation. She does not conquer, she cultivates.

\section{The context of influence}

Like the knight from La Mancha, in this essay I do battle with a concept of "influence" whose sinfulness might not be apparent to the reader. To accept my banishment of the casual meaning of "influence" as action at a distance, the reader must agree with me that history of social science is in need of detailed studies of scholarly communication and of the ways scholars craft scientific and public culture. My proposal is not to banish "influence" from our lexicon, instead I want us to enrich our lexicon with many "influences." I suggest that we must adjectify the noun to activate empirically rich historical analyses. Of the many possibilities open before us, I tabled two. I proposed a concept of "personal influence" to aid our study of how various sources of information 
enter our lives, and a concept of "social influence" to direct our attention to how collective belonging and identity is nurtured and restored.

Historians of science have usefully described thought collectives, invisible colleges and epistemic communities (Fleck 2012[1935]; Crane 1972; Knorr Cetina 1999;). These collectives were demarcated by citation and collaborative networks, by research practices, by instrumentation or model organisms. My discussion above, inspired by reading some classics of social psychology, suggests that there is an alternative frame to write about community in science. The problem I posed in this essay is how to study science as a collective endeavor that is as much about truth making as it is about being with others. Writing from the context of influence we can unpack interpersonal relations and appreciate how informality and common purpose shape and animate scholarship.

I must close this reflection with an admission of defeat. I had hoped that after eight thousand words laboring to secure a language to describe influence, I would be able to unveil and celebrate Mary's palpable importance to me and to others. It is apparent that an accurate appreciation of Mary's influence(s) has eluded me. My analysis is incomplete but one measure of her powers is well documented in this essay. She has made me, and others, think boldly and carefully about the craft of history by posing difficult and penetrating questions. Without her provocation I would not have asked any questions about influence, without her example I would not have thought to make a case for and against. She will likely not agree with many of my conclusions but this is a Marian essay. 


\section{References}

Ambrose, Kirk (2012) “Influence” Studies in Iconography 33, Special Issue Medieval Art History Today-Critical Terms: 197-206.

Asch, Solomon (1955) "Opinions and social pressure" Scientific American 193 (5): 3135 .

Asch, Solomon (1956). "Studies of independence and conformity. A minority of one against a unanimous majority" Psychological Monographs. 70 (9): 1-70.

Bigaj, Tomasz (2012) “Causation Without Influence” Erkenntnis 76(1): 1-22

Boring, Edwin G. (1964) “Cognitive Dissonance: Its Use in Science” Science 145, n. 3633: 680-685.

Bornmann, L. and Mutz, R. (2015) “Growth rates of modern science: A bibliometric analysis based on the number of publications and cited references" Journal of the Association for Information Science and Technology 66: 2215-2222.

Carnegie, Dale (1936) How to Make Friends and Influence People. New York : Simon and Schuster.

Crane, Diana (1972) Invisible colleges. Diffusion of knowledge in scientific communities. Chicago: University of Chicago Press.

Cremaschi, Sergio, and Marcelo Dascal. (1996) "Malthus and Ricardo on Economic Methodology." History of Political Economy 28(3): 475-511.

Dein, Simon (2001) "What Really Happens When Prophecy Fails: The Case of Lubavitch" Sociology of Religion 62(3): 383-401.

Depoortere, Christophe (2002) "On Ricardo's Method: The Unitarian Influence Examined" History of Political Economy 34(2): 499-504. 
Festinger, Leon; Riecken, Henry W.; Schachter, Stanley (1956). When Prophecy Fails: A Social and Psychological Study of a Modern Group that Predicted the Destruction of the World. University of Minnesota Press.

Festinger, Leon (1962) A Theory of Cognitive Dissonance. Palo Alto: Stanford University Press.

Forman, Paul (1971) “Weimar Culture, Causality, and Quantum Theory, 1918-1927: Adaptation by German Physicists and Mathematicians to a Hostile Intellectual Environment" Historical Studies in the Physical Sciences 3: 1-115.

Fleck, Ludwik (2012[1935]) Genesis and Development of a Scientific Fact. Chicago: University of Chicago Press.

Gitlin, Todd (1978) "Media Sociology: The Dominant Paradigm.” Theory and Society 6(2): 205-253.

Haney, C.; Banks, W. C.; Zimbardo, P. G. (1973). "Interpersonal dynamics in a simulated prison". International Journal of Criminology and Penology 1: 69-97.

Howlett, Peter and Mary S. Morgan (2011) [eds] How Well Do Facts Travel? Cambridge: Cambridge University Press.

Katz, Elihu \& Lazarsfeld, Paul K. (1955). Personal Influence, the Part Played by People in the Flow of Mass Communications. New York: Free Press.

Knorr Cetina, Karin (1999). Epistemic Cultures: How the Sciences Make Knowledge. Cambridge, MA: Harvard University Press.

Kramer, Lawrence (2011). "Influence." Interpreting Music. University of California Press, pp.113-127. 
Larsen, P. O., \& von Ins, M. (2010). The rate of growth in scientific publication and the decline in coverage provided by Science Citation Index. Scientometrics 84(3), 575-603.

Lewis, David (2000) “Causation as Influence” The Journal of Philosophy 97(4) Special Issue: Causation: 182-197.

Mahoney, Michael J. (1979) "Review Paper: Psychology of the Scientist: An Evaluative Review" Social Studies of Science 9(3): 349-375.

Mata, Tiago (forthcoming) "Reading Popular Histories of Economics" in Weintraub, E. Roy and Duppe, Till (eds.), The Contemporary Historiography of Economics. London: Routledge.

Milgram, Stanley (1963). "Behavioral Study of Obedience". Journal of Abnormal and Social Psychology 67 (4): 371-378.

Morgan, Mary S. (2011) “Travelling Facts” in How Well Do Facts Travel? Cambridge: Cambridge University Press, pp. 3-40.

Morgan, Mary S. (2012) The World in the Model: How Economists Work and Think. Cambridge: Cambridge University Press.

Moss, Laurence S. (1991) "Thomas Hobbes's Influence on David Hume: The Emergence of a Public Choice Tradition" History of Political Economy 23(4): 587-612.

Pesciarelli, Enzo (1999)"Aspects of the Influence of Francis Hutcheson on Adam Smith" History of Political Economy 31(3): 525-545.

Poovey, Mary (1998) A History of the Modern Fact. Problems of Knowledge in the Sciences of Wealth and Society. Chicago: University of Chicago Press.

Price D J de S. (1963) Little science. Big Science. New York: Columbia University Press. 
Russell, Paul (1985) "Hume's Treatise and Hobbes's the Elements of Law." Journal of the History of Ideas 46, no. 1: 51-63.

Schaffer, Jonathan (2001) “Causation, Influence, and Effluence” Analysis 61(1): 11-19.

Wise, M. Norton (2011)“Forman Reformed, Again” in Weimar Culture and Quantum Mechanics, Selected Papers by Paul Forman and Contemporary Perspectives on the Forman Thesis, C. Carson, A. Kojevnikov, and H. Trischler (ed.s) London: Imperial College Press. pp. 415-432.

Woodward, James (2017) "Scientific Explanation", The Stanford Encyclopedia of Philosophy, Edward N. Zalta (ed.), <https://plato.stanford.edu/archives/fall2017/entries/scientific-explanation/>. 


\section{List of figures and tables}

Figure 1. "Influence" is becoming ever more influential. Number of articles mentioning "influence." Source google scholar, using "academic-keyword-occurrence”, available at https://github.com/Pold87/academic-keyword-occurrence accessed February 2018,. 


\begin{tabular}{|l|l|l|}
\hline & Influence, classic account & Travelling Facts \\
\hline Ontology & Concepts and beliefs & Things and doings \\
\hline Agency & Scholars & Distributed, people and things \\
\hline Criteria of association & Resemblance of beliefs & $\begin{array}{l}\text { Prior identification of facts } \\
\text { paired with account of } \\
\text { integrity }\end{array}$ \\
\hline Mechanism & None & $\begin{array}{l}\text { Travel and accounts of } \\
\text { fruitfulness }\end{array}$ \\
\hline Teleology & $\begin{array}{l}\text { Ideas are systematic and } \\
\text { authoritative }\end{array}$ & Knowledge is fruitful \\
\hline
\end{tabular}

Table 1. Two accounts of the movement of ideas across time and space. 
Principle 1 - The only way to get the best of an argument is to avoid it.

Principle 2 - Show respect for the other person's opinions. Never say, "You're wrong."

Principle 3 - If you are wrong, admit it quickly and emphatically.

Principle $4-$ Begin in a friendly way.

Principle 5 - Get the other person saying "yes, yes" immediately.

Principle 6 - Let the other person do a great deal of the talking.

Principle 7 - Let the other person feel that the idea is his or hers.

Principle 8 - Try honestly to see things from the other person's point of view.

Principle 9 - Be sympathetic with the other person's ideas and desires.

Principle 10 - Appeal to the nobler motives.

Principle 11 - Dramatize your ideas.

Principle 12 - Throw down a challenge."

Table 2. Compilation of maxims from Dale Carnegie (1936) How to Win Friends and Influence People. 


\begin{tabular}{|l|l|l|}
\hline & Personal influence & Social influence \\
\hline $\begin{array}{l}\text { Definition of } \\
\text { "influence" }\end{array}$ & $\begin{array}{l}\text { Capacity of some } \\
\text { individuals (by social } \\
\text { position, temperament or } \\
\text { expertise in persuasion) }\end{array}$ & $\begin{array}{l}\text { Quality of a group underpinning its } \\
\text { cohesion (revised when beliefs are } \\
\text { under threat) }\end{array}$ \\
\hline Methodology & $\begin{array}{l}\text { Survey, structured } \\
\text { interviews }\end{array}$ & Ethnography, biographical \\
\hline $\begin{array}{l}\text { Level(s) of } \\
\text { analysis }\end{array}$ & $\begin{array}{l}\text { Record of attitudinal change } \\
\text { and what informed it; } \\
\text { demographics of } \\
\text { "influentials" }\end{array}$ & $\begin{array}{l}\text { Cooperative activities of groups and } \\
\text { their justifications }\end{array}$ \\
\hline $\begin{array}{l}\text { Insight for } \\
\text { sociology and } \\
\text { history of } \\
\text { science }\end{array}$ & $\begin{array}{l}\text { Analysis of scholarly } \\
\text { communication }\end{array}$ & $\begin{array}{l}\text { Analysis of regulation of epistemic } \\
\text { communities }\end{array}$ \\
\hline
\end{tabular}

Table 3. Scheme of the meanings and uses of "influence" as action up close. 


\begin{tabular}{|c|c|c|c|}
\hline Cites & Authors & Title & $\begin{array}{l}\text { Year of } \\
\text { publication }\end{array}$ \\
\hline 1027 & $\begin{array}{l}\text { MS Morgan, M } \\
\text { Morrison }\end{array}$ & $\begin{array}{l}\text { Models as mediators: Perspectives on natural and } \\
\text { social science }\end{array}$ & 1999 \\
\hline 985 & MS Morgan & The history of econometric ideas & 1992 \\
\hline 820 & $\begin{array}{l}\text { C Baden-Fuller, } \\
\text { MS Morgan }\end{array}$ & Business models as models & 2010 \\
\hline 383 & $\begin{array}{l}\text { M Morrison, MS } \\
\text { Morgan }\end{array}$ & Models as mediating instruments & 1999 \\
\hline 246 & MS Morgan & $\begin{array}{l}\text { The world in the model: How economists work } \\
\text { and think }\end{array}$ & 2012 \\
\hline 224 & $\begin{array}{l}\text { DF Hendry, MS } \\
\text { Morgan }\end{array}$ & The foundations of econometric analysis & 1997 \\
\hline 220 & $\begin{array}{l}\text { MS Morgan, L } \\
\text { Kruger, G } \\
\text { Gigerenzer }\end{array}$ & The probabilistic revolution & 1987 \\
\hline 184 & $\begin{array}{l}\text { MS Morgan, M } \\
\text { Rutherford }\end{array}$ & $\begin{array}{l}\text { From interwar pluralism to postwar } \\
\text { neoclassicism }\end{array}$ & 1998 \\
\hline 174 & MS Morgan & Models, stories and the economic world & 2001 \\
\hline 150 & MS Morgan & $\begin{array}{l}\text { Experiments Without Material Invention: Model } \\
\text { Experiments,Virtual, Experiments andVirtually } \\
\text { Experiments }\end{array}$ & 2000 \\
\hline
\end{tabular}

Table 4. Data from Google Scholar with publications of Mary S. Morgan scrapped by Publish and Perish and ranked by number of citations, accessed September 2017. 